\title{
Purificación y sacrificio. El orfismo y su herencia dionisiaca-apolinea
}

\section{E. Sebastián Lomelí Bravo}

\begin{abstract}
Ahora, pues, tañedor de la lira, a ti, que grata melodía cantas, mi ánimo me incita a decir lo que jamás antes referí, cuando, espoleado por el aguijón de Baco y del soberano Apolo, mencioné los dardos que hacen estremecerse, remedios para los mortales, y luego los pactos juramentados para los iniciados.
\end{abstract}

Argonáuticas órficas, vv. 8-13

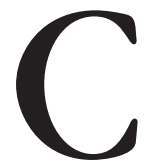

on las siguientes líneas se pretende ensayar las relaciones entre el orfismo y la pareja de Apolo y Dioniso. Esto tiene la finalidad de robustecer la tesis de Guthrie, ${ }^{2}$ según la cual Orfeo habría sido originariamente una figura del espectro de la religión diurna de Febo, quizá uno de sus sacerdotes, que pretendió reformar el culto báquico.

Esto no significa que nos ocuparemos de Orfeo como un hombre real y externo a los textos. En cambio, nos referiremos al Orfeo órfico, aquel que aparece en la doctrina. Por ello es que buscaremos en el mito y en las creencias de esta religión mistérica elementos que nos permitan afirmar cómo es que el poeta jugó el papel de intermediario entre Febo y Baco.

La tesis que nos guía en el presente texto es la siguiente: el orfismo pretendió descifrar el misterio de la bacante -ése que incumbe a la caída de la frontera entre los hombres y los dioses- en una clave sui generis, a saber: la eliminación de la violencia sacrificial. Esto sólo pudo fundarse en la creencia de que la divinidad ya estaba en el creyente y, por tanto, no hacía falta exigirle que se presentase. De este modo, el órfico pretendía ser dios o, mejor dicho, reconocer al dios en sí mismo. Al lograrlo no tendría que derramar más sangre, y mucho menos practicar el rito furioso por el que originalmente se manifestaba Dioniso.

${ }^{1}$ Agradezco sinceramente los comentarios que las doctoras Elsa Cross y María Antonia González Valerio hicieron al presente ensayo.

${ }^{2}$ W. K. Guthrie, Orfeo y la religión griega. Prefacio de Larry J. Aldernik. Trad. de Juan Valmard. Madrid, Siruela, 2003, p. 82. 
Cuando se afirma que el orfismo reformó la religión dionisiaca, la pregunta que debe aparecer en seguida es en dónde, pues se encuentra lo divino de Dioniso en esta nueva lectura del dios. No cabe duda de que la cuestión no debe pretender ver una identidad en la divinidad de Baco; la unidad de los dioses es una hipótesis con la que uno no puede contar al estudiar la religión griega, particularmente en el caso de esta divinidad, la cual cargó con el más contradictorio manojo de epítetos del panteón heleno. ${ }^{3}$ Aun así, la pregunta sigue vigente: ¿qué de la divinidad dionisiaca permitió su inclusión en la creencia órfica?

La vida de Orfeo puede darnos una pista. Si bien no puede justificarse que sus seguidores hayan sido contemporáneos suyos, y mucho menos que el mismo Orfeo haya sido más que un personaje mítico, la historia que conservamos de ese cantor tracio se vincula de modos ambiguos, aunque completamente determinantes, con Dioniso. No sólo la creencia los remite a ambos a Tracia, ${ }^{4}$ además la muerte de Orfeo muestra una intrincada red de simbolismos que lo arrancan de la típica imagen apolínea y lo entregan al rito báquico de modo casi inequívoco.

Detienne sigue estos parentescos en su libro La escritura de Orfeo. Llama la atención primero sobre la efigie del poeta; si bien su apariencia de hombre joven y bello siempre acompañado de una lira lo confunde con el mismo Apolo, a esta imagen debemos añadir las resonancias que pueda tener del joven Dioniso, cuya representación se volvió cada vez más común desde la Época clásica. También Harrison había apuntado esta semejanza al contrastarlo con el Baco de Eurípides; con ese joven de apariencia dulce y

\footnotetext{
${ }^{3}$ Se le llama "dispensador de bienes", "liberador de toda pena y cuita", "el que sana y relaja" y "el lleno de gracias"; se opone a ello un registro de nombres cuyo único parangón se encuentra entre las bestias más terribles del inframundo: "el descuartizador de hombres", "el que come carne cruda", "el que encuentra placer en el hierro y la sangre vertida". Véase Walter. F. Otto, Dioniso. Mito y culto. Trad. de Cristina García Ohlrich. Madrid, Siruela, 2001, p. 85.

${ }^{4}$ Se conservan registros de un intenso culto dionisiaco en Tracia, aunque la tradición más extendida ubica su patria en Tebas. Por otro lado, algunos descubrimientos arqueológicos rastrean a Dioniso en Creta desde las épocas minoica y micénica, lo cual podría reforzar la tesis de que la supuesta extranjería del dios es uno de los elementos propios de su divinidad. Marcel Detienne interpretó, por ejemplo, que en esa característica se develaba el esencial oscilar de este dios entre la presencia y la ausencia, entre la extrañeza y el reconocimiento (cf. M. Detienne, Dioniso a cielo abierto. Los mitos del dios griego del desenfreno. Trad. de Margarita Mizraji. Barcelona, Gedisa, 2003 , pp. 30 y ss.)
} 
afeminada, ${ }^{5}$ demasiado sereno para la situación comparado con el exaltado Penteo. ${ }^{6}$

El segundo punto que muestra esta ambigüedad o tensión es la muerte del poeta. Ésta ocurre a manos de las basárides, o ménades tracias, en una tónica propia de las muertes que rondan el culto dionisiaco. Lo cual levanta la sospecha de la pertenencia de Orfeo a esa constelación de personajes míticos, a los que Dioniso castiga mediante su epifanía destructora encarnada en su cortejo. Así lo hizo con Penteo y con Licurgo, castigó además con la locura a la hijas de Minias, quienes terminaron por matar a sus propios hijos. ${ }^{7}$ Todas estas muertes remiten al despedazamiento del pequeño Dioniso por los Titanes, y por ello no sólo deben de ser considerados únicamente como una venganza por parte del dios, sino como el modo más vehemente y violento en el que éste hace patente su divinidad.

En un fragmento de una tragedia perdida de Esquilo conservamos una narración de la causa de la ira de Dioniso contra Orfeo; el poeta enfureció al dios cuando en el monte Pangeo -donde en otros tiempos Licurgo hizo correr despavorido al pequeño Baco- proclamó a Helios como el más grande de los dioses. ${ }^{8}$ No debe suponerse que el problema aquí haya sido afirmar una jerarquía en el panteón, lo extraño en dado caso es establecerla desde un dios menor, el que, nos recuerda Detienne, ${ }^{9}$ sólo en su identificación con Apolo

5 Algunos estudiosos han comparado la apariencia ambigua de Dioniso con la posible homosexualidad de Orfeo. No obstante, no resulta ser un terreno fácil para establecer comparativos. Por un lado, en el dios la falta de frontera entre los sexos no implica un contacto sexual con hombres, sino la disolución misma de la diferencia, cuestión propia de su epifanía. Por otro lado, la homosexualidad de Orfeo, motivo de bromas por parte de los alejandrinos, fue leída como una consecuencia del dolor por la pérdida de Eurídice. Y si nos atenemos a que no hay pruebas de que el descenso de Orfeo haya sido a causa de su esposa, sino hasta épocas muy tardías (W. K. Guthrie, op. cit., p. 81), esto haría también el tema de su sexualidad una cuestión posterior. Sobre la homosexualidad de Orfeo puede consultarse José Ordoñez Burgos, La poesía órfica y la sabiduría antigua. Chihuahua, Instituto Chihuahuense de Cultura, 2002, p. 29, n. 26 y W. K. Guthrie, op. cit., p. 85.

${ }^{6}$ Jane Ellen Harrison, Prolegomena to the Study of the Greek Religion. Londres, Merlin, 1980, p. 475 y M. Detienne, La escritura de Orfeo. Trad. de Marco Aurelio Galmarini. Barcelona, Península, 1990, p. 95.

${ }^{7}$ Véase W. F. Otto, op. cit., p. 60.

${ }^{8}$ Nos han llegado otras versiones de la muerte de Orfeo que la atribuyen a la ira de las mujeres, o bien porque no las consideró dentro de sus misterios, o porque sedujo a sus esposos y los apartó de ellas (W. K. Guthrie, op. cit., p. 84). Platón escribió que la causa de la muerte fue el castigo por la cobardía de querer bajar al Hades con vida, y no ser lo suficientemente valiente como para morir por el amor que fue a buscar. (Banquete 179d). Isócrates, por su parte, la atribuyó a la impiedad de su credo (Giorgio Colli, La sabiduría griega. Trad. de Dionisio Mínguez. Madrid, Trotta, 1995, vol. 1, 4 [A54]).

${ }^{9}$ M. Detienne, La escritura de Orfeo, p. 104. 
cobra relevancia. ¿Puede leerse entonces la muerte del poeta como un episodio de rivalidad entre estas deidades antagónicas? La cuestión no termina ahí, pues si tomamos como parámetro las teologías órficas, encontramos que Dioniso es el dios central del culto, lo cual podría hacer comprensible su venganza.

Sin embargo, la perplejidad continúa. Si volvemos a mirar en los textos órficos que han sobrevivido hasta nuestros días, encontramos que la centralidad de Dioniso se debe a un trono heredado en seis ocasiones, las cuales se remontan a Fanes, el dios primero. ${ }^{10}$ Aunque el origen de su nombre se les escapa a los filólogos, las fuentes antiguas concuerdan en atribuirle el significado de "aparecer" ( $(\alpha$ ív $\omega)$, pues fue el primero que "brillando" surgió de las tinieblas, o bien porque iluminó la creación. Esta etimología popular permitía que se le llamase a Fanes, Luz o Sol. Aunque esto no implicase su identificación real con el astro, cuya creación debía haber sido posterior. ${ }^{11}$

¿Quién era ese dios superior a Dioniso? Aunque sea sugerente afirmar que se trataba de Fanes, es difícil establecer un vínculo con esta divinidad propia de las teogonías órficas. No sólo nos enfrentamos a la dudosa datación de las llamadas Rapsodias que contenían estas historias míticas. ${ }^{12}$ Además, debe ser tomado en cuenta que es Apolo quien aparece tras la muerte del poeta para encargarse de algunos de los restos.

Si nos atenemos a la rivalidad Apolo-Dioniso, Orfeo emerge como el cuerpo en que ambas deidades luchan entre sí. El despedazamiento sólo sería la consecuencia esperada. Sin posible reunión armónica, cada dios tomó para sí algo del poeta: los restos del cuerpo fueron encontrados en Lesbos por las musas apolíneas $^{13}$ y la lira fue consagrada en un templo de Febo; pero la cabeza de Orfeo -como en el caso del corazón del Dioniso, quien fuera despedazado por

${ }^{10}$ W. K. Guthrie, op. cit., pp. 125 y ss.

${ }^{11}$ Por último, sería bueno apuntar que en el afán órfico de unidad, en algunas ocasiones se identificaba a Fanes con Dioniso. El mito de las generaciones de los dioses narra que Zeus devoró la primera creación y con ello se convirtió él mismo en el creador al volver a generar o, mejor dicho, a vomitar el mundo. Fanes fue también parte del festín, y se llegó a pensar que éste renació en forma de Dioniso (ibid., pp. 148, 149 y 153).

${ }^{12}$ Según Guthrie el orfismo puede ser datado por lo menos desde el siglo vi a. C. No obstante, las teogonías órficas provienen de textos del periodo helenístico y es difícil dilucidar si su contenido pertenece a etapas más antiguas. Uno de los argumentos importantes para la datación es la semejanza de los órficos con filósofos y teósofos $(v$. gr. Epiménides, Ferécides y Empédocles) del siglo v y vi, aunque la constante reescritura de las ideas expuestas en las Rapsodias (texto del que sólo tenemos fragmentos), posiblemente transformó algunos de los elementos. Sobre esta constante revisión y palimpsesto órfico, véase M. Detienne, La escritura de Orfeo, p. 92.

${ }^{13}$ Recuérdese que fuera del mito órfico, los restos de Dioniso Zagreo son recogidos por el mismo Apolo y trasportados a Delfos. Véase W. K. Guthrie, op. cit., p. 133 y Karl Kerényi, Los dioses de los griegos. Trad. de Jaime López-Sanz. Caracas, Monte Ávila, 1991, p. 251. 
los Titanes- se mantuvo íntegra y la llevaron a un templo de Dioniso, donde realizó profecías hasta que Apolo le ordenó abstenerse de sus asuntos. ${ }^{14}$

Orfeo es el doblemente castigado por los dioses que antes le brindaron sus dones. Apolo lo hizo el mejor citarista entre los mortales al heredarle la música que crea armonía, pues no debe olvidarse que Febo no sólo era señalado por los griegos como el cantor que entretenía a los dioses cuando estaban a la mesa, sino además se creía que su música ordenaba el cosmos. ${ }^{15}$ No cabe duda de que algo de esto se nos muestra cuando hayamos múltiples pasajes sobre Orfeo como el siguiente:
Innumerables
pájaros volaban sobre su cabeza,
y saltarines peces
surgían de las aguas azules
para [escuchar] su bello canto. ${ }^{16}$

Todo tipo de seres rondan a Orfeo y olvidan su lugar en el mundo; las bestias no cazan a sus presas, los árboles se desencajan de la tierra y los monstruos se adormecen. Esta imagen perdura en las Argonáuticas, en las cuales, sin importar la versión, Orfeo participa en el viaje a la Cólquide a pesar de su debilidad física, ya que los demás argonautas saben que su música les es aún más necesaria que otro par de brazos fuertes: ellos saben que Orfeo es capaz de infundir el valor en los hombres, y que la belleza de su canto permitirá librarse de peligros como las sirenas y las Rocas Errantes. ${ }^{17}$

Junto con esta magia en la música de Orfeo, la tradición nos ha entregado además la imagen de un cantor que profetiza, que conoce de rituales de purificación y que fue instaurador de misterios e iniciaciones. Consecuentemente, puede preguntarse si estos atributos son dones debidos al mismo dios, es decir, a Apolo, quien le otorgó precisamente la música que se supone acompañó a esos saberes. Una respuesta positiva a esta cuestión la podemos encontrar en Epiménides y Empédocles, quienes invocaban a Apolo Hiperbóreo como protector de sus ejercicios de ascesis y de purificación. Ambos pensadores han

${ }^{14}$ M. Detienne, La escritura de Orfeo, p. 104.

${ }^{15}$ W. F. Otto, Teofanía. El espíritu de la antigua religión griega. Trad. de Juan Jorge Thomas. Madrid, Sexto Piso, 2007, p. 114.

${ }^{16}$ Simónides, fr. 384 (G. Colli, op. cit., vol. 1, 4 [A2]).

${ }^{17}$ Las habilidades de Orfeo son descritas, por ejemplo, en Argonáuticas órficas, vv. 85 y ss., y acerca del poder de su canto sobre los héroes véase 249-ss. (Ocupo la edición de Miguel Periago: Porfirio, Vida de Pitágoras. Argonáuticas órficas. Himnos órficos. Madrid, Gredos, 2002.) Esto también puede encontrarse en la tragedia perdida de Eurípides, Hipsípila, fr. 1, 3, 8-14 (G. Colli, op. cit., vol. 1, 4 [A18]). 
sido vinculados con el orfismo; el primero por ser el antecedente más antiguo dentro de Grecia de las prácticas espirituales de renuncia, ${ }^{18}$ y el segundo por el contenido de su doctrina de la trasmigración de las almas, el tema predominante de la purificación y la prohibición de manchar los altares con sangre. ${ }^{19}$

Por estas razones podríamos asentir, junto con Kirk y Raven, ${ }^{20}$ que la sabiduría órfica estuvo auspiciada por Febo. Sin embargo, aunque éste haya sido reconocido como el dios de la purificación por excelencia, sus ritos no se encontraron relacionados con los misterios. Los cultos mistéricos y catárticos le correspondieron a Dioniso, como dios de la manía sagrada. Por ello es que Rohde creyó más adecuado adjudicar las prácticas de purificación órfica a esta divinidad. Los cultos a Baco, según el filólogo, aseguraban a los creyentes que su alma, al entrar en contacto con el dios, viviría tras la muerte en la isla de los Bienaventurados. ${ }^{21} \mathrm{El}$ iniciado había sufrido una suerte de divinización que le permitía librarse del destino que le aguardaba al resto de los mortales. Esta posibilidad estaba dada por la misma naturaleza de los ritos, pues durante las orgías, los que participaban se encontraban plenos de la deidad por lo menos en dos sentidos. En primer lugar, el trance de la bacante (la locura dionisiaca) no señalaba un disturbio en la mente, sino la posesión por parte del dios (enthousiasmós); ${ }^{22}$ en segundo lugar, sabemos que los rituales báquicos tenían

${ }^{18}$ Véase Erwin Rohde, Psique. La idea del alma y la inmortalidad entre los griegos. Trad. de Wenceslao Roces. México, FCE, 1983, p. 177.

${ }^{19}$ Véase Empédocles, frs. 466, 468, 469 y 470. (La numeración de los fragmentos ocupados aquí es la de G. S. Kirk y J. E. Raven, Los filósofos presocráticos. Trad. de Jesús García Fernández. Madrid, Gredos, 1981.)

${ }^{20}$ Cf. G. S. Kirk y J. E. Raven, op. cit., p. 61.

${ }^{21}$ Esta creencia, como apuntó Rohde, posiblemente se gestó en el dionisismo de Tracia -si aceptamos la tesis de la extranjería del dios- aún antes de dispersarse por la Hélade por el contacto con el culto al dios Zalmoxis, a quien sus fieles (los getas) seguirían al morir. E. Rohde, op. cit., p. 154.

${ }^{22}$ La locura no pertenece al hombre, ni como psyche, ni siquiera como phren o nous. La demencia, cuando es real, es potestad divina. Como apunta Dodds, esta relación entre locura y divinidad no sólo se encuentra en Grecia, sino que puede ser localizada en diversas culturas. Véase E. R. Dodds, Los griegos y lo irracional. Trad. de María Araujo. Madrid, Alianza, 1981, p. 22; y la descripción de los ritos de distintos pueblos análogos a los menádicos en pp. 253 y ss.

Debe señalarse que, si bien Dodds pretende distinguir distintos tipos de locura según el dios que la envía, Ruth Padel no encuentra justificación suficiente para esta taxonomía y, en cambio, propone que detrás de toda demencia los griegos presentían la acción de Dioniso. La tesis de Dodds se sustenta, según la filóloga, en una sobreinterpretación del famoso pasaje del Fedro (244 a), en el que Platón distingue entre las diversas locuras (poética, mántica, telésica y erótica). En este texto sólo se afirma que la poesía se debe a las musas, pero no se nombra a ningún otro dios. Por otra parte, Padel cree que en el mismo vocabulario ocupado para hablar de locura se delata siempre la acción de Dioniso como verdadero dios de la demencia: "[...] se usa el verbo de Dioniso como si 
un significativo sacrificio de bestias que remitía al despedazamiento mítico de Dioniso; la víctima era destrozada y comida cruda durante el trance menádico, con ello se asumía que la divinidad no sólo había sido convocada entre los participantes, sino que, por haber sido ingerida, ésta se encontraría dentro de ellos.

En lo que respecta a la purificación y la mántica, tampoco podemos decir que fuesen potestades únicas de Apolo, pues la locura dionisiaca fue considerada tanto una catarsis -o purificación que arrojaba a los demonios que provocaban alteraciones en el ánimo y el cuerpo- ${ }^{23}$ como también un vehículo para realizar profecías. ${ }^{24}$ De este modo, la herencia apolínea se confunde con la de Dioniso, lo cual hace necesaria la pregunta por aquello que distingue el don de ambas divinidades para, desde ahí, hacer comprensible las motivaciones que llevaron a los órficos a vincularse con ambas figuras.

Puede aventurarse que fue la promesa del contacto con la divinidad lo que atrajo a los órficos a Baco; si uno se atiene con Guthrie a que el poeta fue una figura satelital de Apolo en un principio, entonces podemos verlo con mayor claridad, pues el culto apolíneo se caracterizó por encontrar lo divino en lo más etéreo y espiritual. Como nos dice Otto, el epíteto "el que hiere de lejos" es representativo de esta distancia radical que el dios guardaba respecto de los mortales. ${ }^{25}$ En contraposición, Dioniso se caracteriza por manifestarse invasivamente; satura la mente y el cuerpo de los creyentes. Quizá es por eso que les resultó a los órficos tan seductora esta creencia; con ella podían zanjar el hiato entre los hombres y los dioses.

Lo que quedaría pendiente, en dado caso, es cómo integrar estos extremos, cómo cantar la verdad dionisiaca con el saber musical de Apolo. Entre las modificaciones órficas al dionisismo que saltan a la vista está la conformación de un séquito masculino a diferencia del culto privilegiadamente femenino de Baco. Esto se puede constatar en las vasijas en las que Orfeo aparece rodeado de hombres tracios y en las narraciones socarronas que hacen de él, Ovidio y Virgilio. De hecho, las mujeres circundan a Orfeo en la iconografía sólo

la locura báquica fuera el modelo de todas las otras. Las Erinias, Ares, Apolo: cualquier cosa que les hagan a las mentes de sus víctimas, Dioniso está ahí, en el verbo. Mainás, 'ménade', la celebrante de Dioniso, significa 'mujer loca'" (R. Padel, A quien los dioses destruyen. Elemento de la locura griega y trágica. Trad. de Gladys Rosemberg. México, Sexto Piso, 2005, p. 56.

${ }^{23}$ Sobre la purificación por el éxtasis puede verse E. Rohde, op. cit., $\mathrm{p} 172$ y E. R. Dodds, op. cit., p. 254. Para el presente ensayo es importante señalar que la locura purificadora parece haber sido uno de los elementos del dionisismo que eliminaron los órficos. Líneas abajo se lanza una hipótesis para comprender tal ausencia.

${ }^{24}$ Eurípides, Ba., 302. (Cito la edición de Carlos García Gual y Luis Alberto de Cuenca y Prado: Eurípides, Tragedias. Madrid, Gredos, 2008, vol. III.)

${ }^{25}$ W. F. Otto, Teofanía, p. 114. 
cuando se insinúa su muerte. Únicamente las musas, de entre todas las figuras femeninas, le fueron propicias. ${ }^{26}$

Las implicaciones de la ausencia de lo femenino no son superficiales, pues al desaparecer la bacante, también se esfuma la demencia; Orfeo no canta la grandeza de la locura ni la embriaguez, sino a la pureza venida del ascetismo. Esta abstención no puede confundirse con la moderación implícita en el "todo con medida" délfico, pues lo que se presentaba bajo la renuncia órfica apenas tiene parangón con la religiosidad tradicional griega. ${ }^{27}$ Paradójicamente, el ascetismo estaba cimentado en la vivificación del mito de la sanguinaria muerte de Dioniso Zagreo, el cual sustentaba, como ya se mencionó, también los ritos menádicos del sparagmós y de la manducación del toro en Creta. ${ }^{28}$ La posibilidad de que la asimilación de este mito no condujese al mismo resultado se encuentra en el agregado que los órficos hicieron a la narración. El mito cuenta que los Titanes atrajeron con juguetes a Zagreo ("el cazador") para descuartizarlo. Cuando Zeus furioso se enteró del crimen, los castigó fulminándolos con un rayo, las cenizas de los criminales y la víctima se mezclaron. Esta mezcla fue, según los órficos, la materia de la que nació la raza de los mortales: los hombres comparten la naturaleza divina y pura de Dioniso, y la propia de la impureza del homicida, a la que se suma un carácter terreno, por ser los Titanes hijos de la Tierra. El cuerpo y su amor a lo perecedero del mundo sublunar es la herencia que les dejaron a los hombres. El alma, por su parte, esa que ya los dionisiacos habían asumido como entidad que podía entrar en contacto con el dios, es el don que Zagreo cedió. ${ }^{29}$

\section{4 у 6.}

${ }^{26}$ Remito a las ilustraciones en W. K. Guthrie, op. cit., pp. 86, 87, 88 y a las láminas

${ }^{27}$ Es importante resaltar que la purificación en ritos de coribantismo, como el de las bacantes, se realizaba mediante un trance inducido por la danza y la música de címbalos, tambores y flautas. La lira apolínea no tenía lugar en estos ritos. $C f$. E. Rohde, op. cit., n. 137.

${ }^{28}$ Albert Loisy, Los misterios paganos y el misterio cristiano. Trad. de Ana P. de Goldar. Barcelona, Paidós, 1990, p. 31.

${ }^{29}$ Se cree factible que en los ritos mistéricos órficos se ocuparon juguetes para simular el engaño de los Titanes. Los argumentos a favor y en contra pueden encontrarse en W. K. Guthrie, op. cit., pp. 175 y ss.

Además, el descuartizamiento podría haber sido vinculado con la numerología apolínea. Detienne reporta que en Olbia (Mar Negro) fueron encontradas tablillas órficas junto a un templo de Apolo, en las cuales se había inscrito de un lado "Dioniso" y del otro una figura rectangular dividida en siete partes, el cuál es el número de Febo. A la sazón cita uno de los fragmentos órficos "De los miembros del niño, los Titanes hicieron siete partes" (Kern, 210a). Véase M. Detienne, op. cit., p. 97 y Jean-Paul Vernant, Mito y religión en la Grecia antigua. Trad. de Salvador María del Carril. Barcelona, Ariel, 1999, p. 76. 
Cuando Jane Harrison ${ }^{30}$ pretende sintetizar el núcleo de la religiosidad órfica, dice que esta doctrina no pretendió sólo encontrar la bienaventuranza al descender al Hades, a lo cual ya aspiraban los griegos mediante el culto dionisiaco. Esa vida futura, semejante a la de los dioses, debía ser para los órficos la consecuencia de la divinidad que le pertenecía al hombre por su mismo origen. Para los seguidores de Orfeo, la divinidad no sólo podía adentrarse en el creyente, sino que el hombre mismo es un dios extraviado en esta tierra, ${ }^{31}$ entregado a un cuerpo titánico que mancilla su naturaleza superior. Esta impureza es la que debe purgar el órfico; su vida terrena debe encaminarse a la purificación de esa otra naturaleza diversa a la divina.

La relevancia del tema de la pureza, sin embargo, no puede decirse que haya sido exclusiva de los órficos. El griego común vivía inmerso en ritos de purificación, algunos de los cuales lo acompañaban como hitos en los ciclos naturales de la vida ( $v$. $g r$., nacimiento, parto, muerte, aniversarios luctuosos), pero otros se encontraban en momentos excepcionales, como la lustración previa a todo sacrificio y los ritos especiales para limpiar al homicida de su mancha. A la par, el hombre estaba expuesto a múltiples situaciones que le arrebataban la pureza (al cometer homicidio, cuando un hombre se bañaba en agua que había usado una mujer, cuando alguien se cortaba las uñas en un festín, etcétera). Debe apuntarse también que la religiosidad griega tras la época homérica centralizó cada vez más el conflicto entre pureza y mácula, por lo cual, y consecuentemente, fueron desarrollados un sinfín de ritos que pretendían lavar a los hombres (con agua, azufre, higos, humo, sangre, etcétera).

Existía, sin embargo, una gran diferencia entre las purificaciones iniciáticas (ritos eleusinos, báquicos u órficos) y las pertenecientes al culto cotidiano, pues estas últimas no tenía repercusión fuera de la vida misma; tanto el hombre contaminado como el puro terminarían en el Hades posiblemente reducidos a una sombra despersonificada. ${ }^{32}$ La purificación era llevada a cabo para evitar desgracias, ya que el contaminado atraía los males a sí mismo, a los que lo rodeaban e incluso a la ciudad donde habitaba.

Los filólogos siguen discutiendo sobre la naturaleza y causas de la contaminación; en algunos casos parece que la impureza es simple suciedad física, en

${ }^{30}$ J. Harrison, op. cit., p. 477.

${ }^{31}$ Éste es otro de los elementos doctrinales que ha llevado a concluir a los estudiosos los posibles vínculos entre los órficos y Empédocles: "Yo soy ahora uno de ellos, desterrado de los dioses y errabundo, yo que puse mi confianza en la furiosa discordia" (fr. 471).

${ }^{32}$ En esto parece que se mantuvo vigente la narración homérica del viaje de Odiseo al Hades (Odisea, XI). Sólo a los héroes y a los emparentados con los dioses les podía esperar una vida venturosa en el Elíseo. Una excepción a estas dos posibilidades le fue reservada a los que habían sido asesinados, ellos se convertían en espíritus de venganza que debían ser aplacados con el castigo o purificación del homicida. Véase E. Rohde, op. cit., pp. $120 \mathrm{~b}$ y ss. 
otros la venganza de algún demonio agravado; aparece también con la ambigüedad de ser causa de desgracias o efecto de las mismas, sin que esto posibilite señalar un agente específico de la contaminación. ${ }^{33}$ Lamentablemente, éste no es lugar para exponer y comparar los argumentos. Sin embargo, haremos una breve síntesis de la tesis de Vernant sobre el vínculo entre la impureza y lo sagrado, pues la consideramos fructífera para acercarnos al tema de la pureza órfica. Lo cual no significa que aquí se afirme que se trate de una propuesta que de hecho pueda explicar completamente el heterogéneo fenómeno de la purificación en la Grecia antigua. ${ }^{34}$

Para Vernant, la contaminación se debe al contacto entre realidades divergentes, $v$. gr., lo vivo con lo muerto, lo divino con lo humano, lo masculino con lo femenino. Desde esta perspectiva, la contaminación no tiene autor, no tiene estrictamente un carácter moral ni físico; la impureza seguiría en mayor medida una lógica de lo elemental y lo compuesto, que a la del pecado y la redención. Pero aquí no se trata de la mezcla entre cualquier tipo de elementos, propiamente la pérdida de la pureza ocurre en el contacto entre algo profano y lo sagrado, donde esto último puede ser un objeto consagrado a un demonio o divinidad. Por ello, para Vernant la estructura de la prohibición y la de la pureza están vinculadas:

Desde una de las perspectivas del pensamiento religioso, la "pureza" de una potencia divina se mide por el número y el rigor de las prohibiciones que la protegen. A medida que esta pureza se incrementa se

${ }^{33}$ Aunque se han establecido paralelismos con el pecado, la impureza pertenece a una lógica distinta, y justo la distinción se evidencia en la imposibilidad de atribuirla a un campo subjetivo y moral. Esto se dice no sólo por la falta de sentimiento de culpa, sino porque hay muchos casos en los que la mácula es adquirida sin atribución de voluntad a quien la adquiere, e incluso puede ser entendida con mayor facilidad desde una lógica del "contagio" de algún mal, en lugar de pensarla desde lo que entendemos actualmente por cometer una falta.

${ }^{34}$ Se tomaron en cuenta para este ensayo tres distintas propuestas: $a$ ) La de E. Rohde, quien entiende la impureza como consecuencia de la acción de un daimon sobre un hombre cuando éste ha entrado en contacto con su morada, animales destinados a su sacrificio, etcétera. También considera que el asesino es impuro en tanto el muerto exige se vengue el crimen. Véase E. Rohde, op. cit., pp. 172 y 173 ; b) Para Moulinier (citado por Vernant) la contaminación no puede ser efecto de daimones, pues los textos señalan siempre la intervención de un elemento físico, como si se tratase de suciedad. Por otro lado, la impureza por las almas en búsqueda de venganza sólo es atestiguada en la tragedia, y $c$ ) La tercera vía es la de Vernant, que exponemos en el cuerpo del ensayo. Véase J. P. Vernant, Mito y sociedad en la Grecia antigua. Trad. de Cristina Gázquez. Madrid, Siglo XXI, 1987, pp. 103 y ss. Por fines de unidad del presente texto, tampoco se contrasta la propuesta de Vernant con la de Dodds, quien resalta el carácter "externo" de la mácula, frente al malestar "interno" de la conciencia que implica el pecado. 
multiplican, en las relaciones del dios con los hombres, las ocasiones de contaminación sacrílega. Pero al término de esta progresión los dos polos opuestos de lo puro y lo contaminado se juntan y se confunden. En último extremo aparece como puro lo que está totalmente prohibido, es decir, aquello con lo que el hombre no debe jamás entrar en contacto. ${ }^{35}$

Ensayemos sobre esta tesis; para la religión de la polis el hombre mantenía una diferencia irreductible con lo divino, y esto a pesar de la humanización de estos. Sólo los héroes y los semidioses podían habitar en torno a los dioses e incluso gozar de su bienaventuranza. Los órficos, como ya apuntamos, se asumían compuestos de divinidad y de entidades telúricas. Según los estudiosos, ${ }^{36}$ esta dualidad de naturaleza señalaba la mácula original con la que había surgido la raza de los mortales; la composición humana es signo de impureza originaria y no la causa de ella, es decir, la impureza no venía inicialmente de la mezcla entre las cenizas de Dioniso y los Titanes, sino porque éstos habían dado muerte al dios niño.

Intuitivamente podría afirmarse que la impureza que el órfico deseó lavar fue el asesinato, y no la mezcla. Pero, ¿por qué dar muerte causaría impureza? Parece evidente que descuartizar a una divinidad, arrancarla de su bienaventuranza, no podría ser más que un acto nefasto, pero esto no explica la razón por la que se suma a esa clase de eventos que ensucian al hombre. Para Vernant, sin embargo, el homicidio se entiende desde la lógica de la contaminación que ha establecido, pues el asesinato no es otra cosa sino un choque violento entre realidades disímiles: la sangre se derrama en la tierra, la vida es golpeada por la muerte y, en el caso de la muerte de Dioniso Zagreo, la bienaventuranza con la mortalidad y la divinidad con la naturaleza titánica.

Aunado a esto, puede decirse que la lustración o lavado de la mancha tenía la intención de separar aquello que había sido mezclado antes. Particularmente, en el caso del homicidio, la sangre de la víctima debía limpiarse de las manos del asesino, pero no bastaba sólo con quitar la mancha física; el asesinato era lavado con la sangre de un animal que, al ser sacrificado, representaba al homicida sufriendo el mismo acto que él había cometido. La sangre purificaba la sangre para el griego común. Para el órfico, sin embargo, parece que un rito de esa naturaleza no tendría eficacia, pues la mancha del homicidio se identifica con el mismo cuerpo del ser humano; para purificarlo haría falta lavarse lo terrenal del hombre, de eso que guarda los vestigios de los Titanes. Ésta fue la base de la ascesis y las reglas de vida que siguieron los órficos.

${ }^{35}$ J. P. Vernant, Mito y sociedad en la Grecia antigua, p. 117.

${ }^{36} \mathrm{Cf}$. E. Rohde, op. cit., p. 182. Y el comentario sobre la frase "[...] pues yo también confieso que soy de vuestra estirpe bienaventurada. Y he pagado la pena por hechos impíos [...]" en las tablillas órficas de Turios (W. K. Guthrie, op. cit., p. 234). 
Ahora, si consideramos que el caso paradigmático de la renuncia órfica fue la prohibición de derramar sangre, ya fuese por asesinato, por comer carne o por sacrificar a los dioses, puede entenderse por qué el rito comúnmente aceptado para limpiar un crimen resultaba no solamente ineficaz, sino que acrecentaba la falta. En un primer plano, podría asumirse que la proscripción de dar muerte a alguien sería una simple repetición del código helénico, en dado caso sólo sería subrayado por la resonancia que este acto tendría con el de los Titanes. No obstante, con esta reducción se ocultaría la relación que esta prohibición podría mantener con las otras dos, es decir, aquellas que se refieren a no matar bestias.

La justificación más respetada de estas prohibiciones se basa en la doctrina de la transmigración de las almas, pues al asumirla se podía suponer que dar muerte a un animal bien podría implicar haber matado a un ser humano que había reencarnado en ese cuerpo. Con este argumento los estudiosos han pretendido explicar la abstención de la carne tanto de los órficos como de los pitagóricos y se ha pretendido ver su fuerza en Empédocles, quien en su obra Purificaciones suscribe dicho argumento bajo una formulación por lo demás dramática:

El padre, pobre necio, levantando en alto a su propio hijo querido, que ha cambiado de forma, lo degüella con actitud de oración; están perplejos cuando sacrifican a su víctima implorante; y él, sordo a sus gritos, la degüella y prepara en sus mansiones un macabro festín $[\ldots]^{37}$

El fragmento continúa con el tono patético con el que se pretende justificar que los animales sacrificados en los altares bien podrían ser nuestros seres queridos. Así, en nada se distinguiría un sacerdote cualquiera de Agamenón, y no habría diferencia entre las víctimas e Ifigenia. No obstante, esta identificación nos suena sospechosa en el momento en que suponemos que resume la creencia esotérica del orfismo. A nuestro juicio, parece más un argumento retórico para convencer a los griegos de una práctica que les era totalmente ajena. ¿Cómo podría ser ésta la justificación entre los iniciados en el orfismo? ¿Acaso no sería mejor explicar que en el ser querido, y en toda víctima, está la divinidad de Dioniso? ¿No nos convertiríamos nosotros mismos en Titanes cuando damos muerte a un ser con vida? A esto debe sumarse que la enunciación tradicional de la prohibición órfica acentúa que el sacrificio "mancha los altares de los dioses con sangre", ${ }^{38}$ y no habla del alma ni de las vidas pasadas

${ }^{37}$ Empédocles, fr. 469.

${ }^{38}$ Platón, "Leyes", en Diálogos. Ed. de Francisco Lisi. Madrid, Gredos, 2008, vol. VIII, VI, 782c. "[... Pitágoras] seguía una línea de conducta tan pura, de aversión a los 
de la víctima. Ahora, si este fuera el caso, y el desprecio al sacrificio fuese el desprecio a reiterar el asesinato de Zagreo, salta a la vista su contraposición con el culto báquico. El violento sacrificio que llevaban a cabo las ménades propiciaba justo la rememoración y la presentación de la divinidad de Dioniso; la víctima era el dios, la sangre, su sangre y, cuando ellas comían su carne, eran Dioniso mismo. Esta naturaleza de la epifanía de Baco fue la que los órficos reformaron. De ser así, se consideraría innecesaria e impía la violencia para comulgar con la divinidad. Al aceptar esto, nos deberíamos preguntar dónde entraban los órficos en contacto con el dios.

Aunque no conocemos el rito de la iniciación órfica, tenemos pistas que nos podrían revelar que se llevaba a cabo una ceremonia en algún aspecto análoga a la menádica. No es seguro si sólo se representaban un sacrificio o si efectivamente de modo excepcional devoraban carne cruda. ${ }^{39}$ Pero si nos atenemos al mito de Zagreo, ese sacrificio iniciático no sería más que un reconocimiento de la divinidad en uno mismo. Fuera de ese primer reencuentro con la divinidad, muy probablemente la creencia en la divinidad en el interior del hombre condujo al iniciado a vivir un culto relativo a sí mismo, al cuidado de sí y a mantener puro lo que en él debía ser tenido como lo superior. ${ }^{40} \mathrm{La}$ ascesis fue el lugar de lo divino, y no el sacrificio.

En resumen, la tesis de Vernant nos ayuda a comprender cómo es que la ascesis de los órficos puede ser entendida como un proceso de purificación, en tanto propone en el fondo una práctica que lava al hombre de su cuerpo

sacrificios y a los que los practicaban, que no sólo se abstenía de los seres animados, sino también que jamás se relacionaba con carniceros ni con cazadores" ( $C f$. Porfirio, Vida de Pitágoras, 7).

${ }^{39} C f$. fr. 3 de Cretenses de Eurípides, donde el iniciado dice haber vivido como Zagreo noctívago y participado en banquetes de carne cruda antes de purificarse, vestir túnicas blancas y rehuir a comer "manjares que en un tiempo tuvieron vida". Frente a estas posible prueba, puede recordarse que Empédocles (fr. 466) describe una época dorada en la que la prohibición de derramar sangre llevaba a los adoradores a representar la escena del sacrificio con imágenes.

${ }^{40}$ En contraposición puede señalarse que lo divino en la ménade no se identificaba con el alma, sino con una pérdida de fronteras entre lo humano, lo divino y lo animal. Dioniso exigía actos que socavaban el orden humano, que llevaban a sus ménades a los límites, no sólo de la polis, sino de la humanidad: la bacante es comparada constantemente con animales, con leonas furiosas y con ciervas ("iAcudid, rápidas perras de la Rabia [Lýssa], acudid al monte, donde tienen su cortejo las hijas de Cadmo! Ba., 978). $C f$. J. P., Vernant, La muerte en los ojos. Figuras del otro en la antigua Grecia. Trad. de Daniel Zadunaisky. Barcelona. Gedisa, 2001, pp. 16 y 40, y W. F. Otto, Dioniso. Mito $y$ culto, p. 61 . 
titánico, que separa aquello que fue mezclado doblemente; por el asesinato de Zagreo y por el rayo de Zeus que fulminó a los culpables. Ahora, esta tesis nos permite remontarnos desde la prohibición del consumo de carne - por ser reiteración del homicidio originario- a una mejor comprensión de la reforma del dionisismo: gracias a la idea de contaminación, los órficos no podían aceptar al Dioniso que libera al hombre de todas las fronteras que lo ciñen (ciudad-silvestre, humano-animal y humano-dios), puesto que no aceptarían que cayese la frontera entre Dioniso y los Titanes, es decir, entre el espíritu y el cuerpo. Mejor dicho, para ellos la destrucción de la frontera entre el dios y los hijos de la Tierra era el principio del extravío del hombre respecto a lo divino. En ese sentido, la ascesis era la reconstrucción de la frontera para poder encontrar la identidad de Dioniso con el alma del hombre.

Tras esta recapitulación del dionisismo, cerremos con una intuición que bien podría dirigir nuestra mirada de vuelta a Apolo. Todo lo dicho hasta aquí nos permite afirmar que la enseñanza de Orfeo - la que fundó el credo órfico- pretendió encontrar una comunión con la divinidad sin la violencia que requería Dioniso; los órficos quisieron adorar al dios que borra las fronteras, pero no aceptaron que la unión tuviese que ser furiosa y sangrienta. En esta reforma el espíritu apolíneo tuvo todo que ver, pues por su nombre los griegos pudieron ver la divinidad en la armonía y la música. Quizá el órfico pretendió con el ascetismo volverse armónico y etéreo como la música para encontrar lo divino. Casi podría decirse que el creyente tendría que sacrificar su vida pública, sus apetitos, la costumbre de la polis y todo lo falto de armonía para no tener que derramar sangre.

La clave del orfismo, como lo han visto muchos poetas y músicos posteriores a los tiempos helénicos, se encontraría en el canto de Orfeo. Puesto que finalmente fue la música de la lira apolínea la que le permitió a Orfeo cruzar las fronteras entre los vivos y los muertos al descender al Hades, entre los humanos y las bestias que se reunían por igual para escucharlo. ¿Podría haber sido la música la que disolviese las fronteras entre los hombre y los dioses, o más precisamente, tendría que volverse musical la vida del órfico para poder entrar en contacto con lo divino? 